\title{
Awards and updates
}

\section{Marcalee Alexander ${ }^{1}$}

Received: 15 April 2018 / Accepted: 15 April 2018

(C) International Spinal Cord Society 2018

I would like to congratulate Julia Bloom as the first recipient of the Spinal Cord Series and Cases award of 750 Euros for the article entitled "Integrated services and early intervention in the vocational rehabilitation of people with spinal cord injuries" [1]. If you have not read it yet, please do! We will be continuing again with this prize and reviewing papers submitted between 1 November 2017 and 31 October 2018 for the 2018 prize and need your input and submission for the articles accepted. Since the recipient of this award is related to the articles that have the most impact, also please make sure to post your share it links on your social media sites, and if you tweet please do so about your articles!

Our first two Point Counterpoint features dwell on the pros and cons of anal examination [2-4] and vertebral surgery for spinal trauma [5-7]. They are quite interesting and thought provoking. Our Pulse articles, which are designed to take a quick snapshot of important topics (e.g., How people do the international standards anal exam? [8] and What is the performance and use of the International Standards for the Assessment of Autonomic Function? [9]), are also excellent reads and are a way to stay up to the minute on new issues. There is a collection of articles related to the International Standards for the Neurologic Assessment of Autonomic Function that will give you the tools to properly perform this important part of your patient's clinical assessment.

It is my goal to make Spinal Cord Series and Cases where you go to learn practical day-to-day tips on patient management. I also want to discuss the most important issues that may impact persons with SCIs. That is why over the next few months we will publish Point Counterpoint and

Marcalee Alexander

spinalcordmd@live.com

1 University of Alabama School of Medicine, Birmingham, Birmingham Veterans Affairs Medical Center, Birmingham, Alabama, USA
Pulse features related to the use of opiates and marijuana in persons with SCI, and to the issue of burnout in health-care professionals. You will be notified about Pulse surveys via ISCOS newsletters and attached links. Additionally, in the next few months, we plan to have a Pulse feature on disasters in persons with SCI and a related special collection of articles and also collections related to SCI in specific countries, beginning with India.

For our journal to grow, however, I need your assistance. I am looking for contributors for papers, good reviewers and people who are interested to serve on the editorial board. I would like to thank Brian Birch, MD, and Vernon Hill, MD, who just joined the editorial board, and Chloe Slocum, MD, Martha Sliwinski, PhD, Mindy Aisen, MD, and Lance Goetz, MD, who have just moved up as Associate Editors. I'd also like to thank you too for reading this editorial. Please reach out and get involved! You will be happy you did.

\section{References}

1. Bloom J, Dorsett P, McLennan V. Integrated services and early intervention in the vocational rehabilitation of people with spinal cord injuries. Spinal Cord Ser Cases. 2017;3:16042. https://doi.org/ 10.1038/scsandc.2016.42.

2. Marino RJ. The anorectal exam is unnecessary. Spinal Cord Ser Cases. 2018;4:3. https://doi.org/10.1038/s41394-017-0013-z.

3. Previnaire JG. The importance of the bulbocavernosus reflex. Spinal Cord Ser Cases. 2018;4:2. https://doi.org/10.1038/s41394017-0012-0.

4. Donovan WH. The importance of the anal exam in neurologic classification of spinal cord injury. Spinal Cord Ser Cases 2018;4. https://doi.org/10.1038/s41394-017-0014-y.

5. ElMasri WS. Traumatic spinal injury and spinal cord injury: point for active physiological conservative management as compared to surgical management. Spinal Cord Ser Cases. 2018;4:14. https:// doi.org/10.1038/s41394-018-0045-z.

6. Kaye ID, Vaccaro AR. The case for surgery of the injured spine in the management of traumatic cord injuries. Spinal Cord Ser Cases. 2018;4:15. https://doi.org/10.1038/s41394-018-0043-1.

7. Abel R. Surgery for spinal injury with neurologic deficit: a matter of opinion. Spinal Cord Ser Cases. 2018;4:16. https://doi.org/10. 1038/s41394-018-0048-9. 
8. Alexander M, Aslam H, Marino RJ. Pulse article: how do you do the international standards for neurological classification of SCI anorectal exam?. Spinal Cord Ser Cases. 2017;3:17078. https://doi. org/10.1038/s41394-017-0015-x.
9. Alexander M, Wecht J, Krassioukov A. International Autonomic Standards Committee. Survey on the current usage of the International Standards for the Assessment of Autonomic Function after SCI (ISAFSCI). Spinal Cord Ser Cases 2017;3:17100. https://doi. org/10.1038/s41394-017-0025-8. 